\title{
A descriptive analysis of the impact of COVID-19 on Emergency Department attendance and visit characteristics in Singapore
}

Mei Qiu Lim ( $\sim$ limmeiqiu@u.duke.nus.edu )

Duke-NUS Medical School

\section{Fahad Javaid Siddiqui}

Duke-NUS Medical School

\section{Seyed Ehsan Saffari}

Duke-NUS Medical School

\section{Andrew Fu Wah Ho}

Department of Emergency Medicine, Singapore General Hospital

Johannes Nathaniel Min Hui Liew

Duke-NUS Medical School

\section{Boon Kiat Kenneth Tan}

Singapore General Hospital

Nicole Simin Sim

Singapore General Hospital

\section{Yuzhen Shen}

Singapore General Hospital

\section{Marcus Eng Hock Ong}

Duke-NUS Medical School

\section{Research Article}

Keywords: COVID-19, coronavirus, emergency department, emergency department attendance, healthcare system, hospital management

Posted Date: October 4th, 2021

DOI: https://doi.org/10.21203/rs.3.rs-149642/v2

License: (c) (i) This work is licensed under a Creative Commons Attribution 4.0 International License.

Read Full License 
Version of Record: A version of this preprint was published at COVID on December 6th, 2021. See the published version at https://doi.org/10.3390/covid1040059. 


\section{Abstract}

Background: The coronavirus disease 2019 (COVID-19) has impacted the utilisation of Emergency Department (ED) services worldwide. This study aims to describe the changes in attendance of a single ED and corresponding patient visit characteristics before and during the COVID-19 period.

Methods: In a single-centre retrospective cohort study, we used descriptive statistics to compare ED attendance, patient demographics and visit characteristics during the COVID-19 period (1 January - 28 June 2020) and its corresponding historical period in 2019 (2 January - 30 June 2019).

Results: Mean ED attendance decreased from 342 visits/day in the pre-COVID-19 period, to 297 visits/day in the COVID-19 period. This was accompanied by a decline in presentations in nearly every ICD-10-CM diagnosis category except for respiratory-related diseases. Notably, we observed reductions in visits by critically ill patients and severe disease presentations during the COVID-19 period. We also noted a shift in ED patient case-mix from 'Non-fever' cases to 'Fever' cases, likely giving rise to two distinct trough-topeak visit patterns during the pre-Circuit Breaker and Circuit Breaker period.

Conclusions: This descriptive study revealed distinct ED visit trends across different time periods. The COVID-19 pandemic caused a reduction in ED attendances amongst patients with low-acuity conditions and those with highest priority for emergency care. This raises concern about treatment-seeking delays and possible impact on health outcomes. The downward trend in low-acuity presentations also presents learning opportunities for ED crowd management planning in a post-COVID-19 era.

\section{Introduction}

The coronavirus disease 2019 (COVID-19) has impacted the utilisation of Emergency Department (ED) services worldwide. Despite the surge in suspected COVID-19 cases, there is global evidence to show that the Emergency Department (ED)'s overall daily attendance has declined [1-4]. Several studies have described significant reductions in visits associated with time-sensitive and life-threatening conditions such as acute myocardial infarction and stroke [5-7], suggesting a worrying trend of patients with acute medical conditions failing to seek critically needed hospital care.

Singapore saw its first COVID-19 case on 23 January 2020. While COVID-19 fatality rates in Singapore remain one of the lowest globally, the city-state nevertheless experienced huge spikes in infections, which prompted two major national interventions to curb the spread of COVID-19 in the community [8]. The first raising of the risk assessment of COVID-19 to Disease Outbreak Response System Condition (DORSCON) Orange on 7 February 2020 caused public fear and concern [9-10]. The second intervention was the Circuit breaker, a partial lockdown on public movement on 7 April 2020, as Singapore observed the peak of daily incidence in April. The local government was aggressive in public education efforts, encouraging residents to stay home and exercise social responsibility, which pre-empted hidden pockets of infected cases from affecting others in the community. The close coordination of different healthcare sectors at the national level allowed continued access to public healthcare services, ensuring that the system had 
sufficient capacity to care for clinically unwell patients at peak infection rates [11]. Following Circuit Breaker, the above measures have helped to keep the number of community infected cases low [12].

At the time of writing, the highly infectious dominant Delta variant is rapidly circulating in the community [13]. Despite being one of the first Asian countries to implement an effective vaccination programme, Singapore may return to a Circuit Breaker when a surge in COVID-19 cases overwhelms hospitals' intensive care unit (ICU) capacity $[13,14]$. As Singapore moves through the ebb and flow of controlling the pandemic, understanding the trend of ED attendance and visit characteristics will facilitate hospital resource planning and allocation in anticipation of worsening COVID-19 situation and future pandemics to come. Hence, this descriptive study aims to understand how attendance of a single ED for both nonemergent and acute life-threatening conditions and corresponding patient visit characteristics changed during the initial stages of COVID-19 period as compared to the pre-COVID-19 period.

\section{Materials And Methods}

\subsection{Study design and setting}

Singapore General Hospital (SGH) is one of Singapore's largest and oldest acute tertiary hospital with 1785 beds in total and its ED sees approximately 130,000 patients annually [15]. In a retrospective study cohort, we compared and described SGH ED attendance, patient demographics and visit characteristics during the COVID-19 period (1 January - 28 June 2020) and its corresponding historical period in 2019 (2 January - 30 June 2019). The studied COVID-19 period was chosen as it represents the changes in ED attendance over the course of time, revealing trends specific to the Pre-Circuit Breaker period and Circuit Breaker period. The pre-Circuit-Breaker period includes both Pre-DORSCON-Orange and DORSCON-Orange periods.

\subsection{Data source and extraction}

Routine and administrative data on ED attendances were extracted from the electronic health intelligence system (eHINTS) at SGH ED. Collected data fields were gender, age, nationality, ethnicity, mode of arrival, patient acuity category scale (PACS), disposition and clinical reason for attendance. This was a service evaluation study which did not require further ethical deliberation by SingHealth Centralised Institutional Review Board (CIRB Ref: 2020/2470).

\subsection{Patient acuity category scale (PACS)}

All public hospitals use PACS to triage patients in the ED [16]. The four main levels of PACS status are Priority 1 (P1) for patients requiring immediate resuscitation; Priority 2 (P2) for non-ambulant patients requiring critical care; Priority 3 (P3) for ambulant patients with mild to moderate symptoms; Priority (P4) for patients with non-emergent conditions which are more appropriately managed in primary health care setting. The febrile counterparts of these categories are P1F, P2F and P3F, respectively.

\subsection{SNOMED CT to ICD-10 Conversion for ED diagnosis}


In our dataset, ED diagnoses were coded and classified according to the Systematized Nomenclature of Medicine Clinical Terms (SNOMED-CT). As International Classification of Diseases, Tenth Revision, Clinical Modification (ICD-10-CM) codes are oriented more for statistical data collection, SNOMED-CT codes were converted to ICD-10-CM and mapped to twenty-one broad ICD-10-CM categories using the SNOMED-CT to ICD-10-CM Map provided by the National Library of Medicine [17]. Only the first matched ICD-10-CM code was kept in instances where multiple possible matches of ICD-10-CM codes to one SNOMED-CT code.

\subsection{Statistical analysis}

ED attendance was reported as mean (and standard deviation and range). Plotted attendance was stratified by year and febrile status. The comparison of categorical variables between pre-COVID-19 and COVID-19 periods were tabulated as frequency reduction and percentage change. All data were deidentified before data processing and analysis in R software (v4.0.0) [18].

\section{Results}

3.1. ED visit records selected for analysis

Out of 120,209 ED visits records extracted, 1029 visit records outside of our study period were excluded. Further exclusion of 4072 duplicate records and 12 distorted records left us with 115,096 ED visit records for analysis; pre-COVID-19 period had 61,576 visit records; COVID-19 period had 53,520 visit records

(Figure 1). This section may be divided by subheadings. It should provide a concise and precise description of the experimental results, their interpretation, as well as the experimental conclusions that can be drawn.

\subsection{Patient demographics and visit characteristics}

Table 1 shows the gross reduction in the number of ED visits at SGH across gender, ethnicity, age groups and Singapore citizens during COVID-19 period. Overall, the mean number of daily ED visits (SD) during the COVID-19 period was 297 (31.8), lower than that during the pre-COVID-19 period $(342,44.9)$. The decline in ED admissions was evident across all ward types except for the infectious disease or isolation wards during the COVID-19 period. 
Table 1. SGH ED patient characteristics during the pre-COVID-19 period in 2019 and COVID-19 period in 2020.

\begin{tabular}{|c|c|c|c|}
\hline \multirow[t]{2}{*}{ Time periods studied } & $\begin{array}{l}\text { Pre-COVID- } \\
19 \text { period }\end{array}$ & $\begin{array}{l}\text { COVID-19 } \\
\text { period }\end{array}$ & \multirow[t]{2}{*}{$\begin{array}{c}\text { \% change in ED attendances as compared to } \\
\text { Pre-COVID-19 period }\end{array}$} \\
\hline & $\begin{array}{l}2 \text { Jan }-30 \text { Jun } \\
2019\end{array}$ & $\begin{array}{l}\text { 1 Jan - } 28 \\
\text { Jun } 2020\end{array}$ & \\
\hline Total No. of ED visits & 61576 & 53520 & $-8056(-13.1 \%)$ \\
\hline $\begin{array}{l}\text { Mean ED attendance }(S D \text {, } \\
\text { range) }\end{array}$ & $\begin{array}{c}342 \\
(44.9,277- \\
427)\end{array}$ & $\begin{array}{l}297(31.8, \\
207-445)\end{array}$ & \\
\hline Demographics & N (\%) & N (\%) & \\
\hline \multicolumn{4}{|l|}{ Gender } \\
\hline Male & $\begin{array}{c}31707 \\
(51.5 \%)\end{array}$ & $\begin{array}{c}28942 \\
(54.1 \%)\end{array}$ & $-2765(-8.7 \%)$ \\
\hline Female & $\begin{array}{c}29869 \\
(48.5 \%)\end{array}$ & $\begin{array}{c}24578 \\
(45.9 \%)\end{array}$ & $-5291(-17.7 \%)$ \\
\hline
\end{tabular}

\begin{tabular}{|c|c|c|c|}
\hline \multicolumn{4}{|l|}{ Age (year) } \\
\hline Median (Q1-Q3², range) & $\begin{array}{c}56(36-70,0- \\
106)\end{array}$ & $\begin{array}{c}55 \text { (35-70, } 0- \\
105)\end{array}$ & \\
\hline $0-10$ & $386(0.6 \%)$ & $216(0.4 \%)$ & $-170(-44.0 \%)$ \\
\hline $11-14$ & $213(0.3 \%)$ & $108(0.2 \%)$ & $-105(-49.3 \%)$ \\
\hline $15-24$ & $5172(8.4 \%)$ & $3970(7.4 \%)$ & $-1202(-23.2 \%)$ \\
\hline $25-34$ & $8448(13.7 \%)$ & $\begin{array}{c}8407 \\
(15.7 \%)\end{array}$ & $-41(-0.5 \%)$ \\
\hline $35-44$ & $7008(11.4 \%)$ & $\begin{array}{c}6916 \\
(12.9 \%)\end{array}$ & $-92(-1.3 \%)$ \\
\hline $45-54$ & $7856(12.8 \%)$ & $\begin{array}{c}6757 \\
(12.6 \%)\end{array}$ & $-1099(-14.0 \%)$ \\
\hline $55-64$ & $\begin{array}{c}10736 \\
(17.4 \%)\end{array}$ & $\begin{array}{c}8884 \\
(16.6 \%)\end{array}$ & $-1852(-17.3 \%)$ \\
\hline$\geq 65$ & $\begin{array}{c}21757 \\
(35.3 \%)\end{array}$ & $\begin{array}{c}18261 \\
(34.1 \%)\end{array}$ & $-3496(-16.1 \%)$ \\
\hline Missing & 0 & 1 & \\
\hline \multicolumn{4}{|l|}{ Citizenship status } \\
\hline Singapore Citizen & $\begin{array}{c}49592 \\
(80.5 \%)\end{array}$ & $\begin{array}{c}41099 \\
(76.8 \%)\end{array}$ & $-8493(-17.1 \%)$ \\
\hline Non-Citizen & $\begin{array}{c}11984 \\
(19.5 \%) \\
\end{array}$ & $\begin{array}{c}12421 \\
(23.2 \%)\end{array}$ & $+437(+3.6 \%)$ \\
\hline \multicolumn{4}{|l|}{ Ethnicity } \\
\hline Chinese & $\begin{array}{c}39663 \\
(64.4 \%)\end{array}$ & $\begin{array}{c}33137 \\
(61.9 \%)\end{array}$ & $-6525(-16.5 \%)$ \\
\hline Indian & $8034(13.0 \%)$ & $\begin{array}{c}7605 \\
(14.2 \%)\end{array}$ & $-429(-5.3 \%)$ \\
\hline Malay & $6603(10.7 \%)$ & $\begin{array}{c}5811 \\
(10.9 \%)\end{array}$ & $-792(-12.0 \%)$ \\
\hline Others & $7276(11.8 \%)$ & $\begin{array}{c}6967 \\
(13.0 \%)\end{array}$ & $-309(-4.2 \%)$ \\
\hline $\begin{array}{l}\text { Visit Characteristics } \\
\text { Mode of arrival }\end{array}$ & N (\%) & N (\%) & \\
\hline Non-ambulance & $\begin{array}{c}52585 \\
(85.4 \%)\end{array}$ & $\begin{array}{c}43239 \\
(80.8 \%)\end{array}$ & $-9346(-17.8 \%)$ \\
\hline SCDF ambulance & $6432(10.4 \%)$ & $\begin{array}{c}7384 \\
(13.8 \%)\end{array}$ & $+952(+14.8 \%)$ \\
\hline
\end{tabular}




\begin{tabular}{|c|c|c|c|}
\hline Private ambulance & $2559(4.2 \%)$ & $2897(5.4 \%)$ & +338 (+13.2\%) \\
\hline \multicolumn{4}{|l|}{ Patient acuity category status ${ }^{2}$} \\
\hline P1 & 9049 (14.7\%) & $\begin{array}{c}5336 \\
(10.0 \%)\end{array}$ & $-3713(-41.0 \%)$ \\
\hline $\mathrm{P} 2$ & $\begin{array}{c}33550 \\
(54.5 \%)\end{array}$ & $\begin{array}{c}28608 \\
(53.5 \%)\end{array}$ & $-4942(-14.7 \%)$ \\
\hline P3 & $\begin{array}{c}16874 \\
(27.4 \%)\end{array}$ & $\begin{array}{c}10486 \\
(19.6 \%)\end{array}$ & $-6388(-37.9 \%)$ \\
\hline $\mathrm{P} 4$ & $345(0.6 \%)$ & $138(0.3 \%)$ & $-207(-60.0 \%)$ \\
\hline $\mathrm{P} 1 \mathrm{~F}$ & $144(0.2 \%)$ & $178(0.3 \%)$ & $+34(+23.6 \%)$ \\
\hline $\mathrm{P} 2 \mathrm{~F}$ & $714(1.2 \%)$ & $1138(2.1 \%)$ & $+424(+59.4 \%)$ \\
\hline P3F & $900(1.5 \%)$ & $\begin{array}{c}7636 \\
(14.3 \%)\end{array}$ & $+6736(+748.4 \%)$ \\
\hline \multicolumn{4}{|l|}{ Disposition } \\
\hline Admitted from ED & $\begin{array}{c}25422 \\
(41.3 \%)\end{array}$ & $\begin{array}{c}23422 \\
(43.8 \%)\end{array}$ & $-2000(-7.9 \%)$ \\
\hline General ward (GW) & $\begin{array}{c}21958 \\
(86.4 \%)\end{array}$ & $\begin{array}{l}20000 \\
(85.4 \%)\end{array}$ & $-1958(-8.9 \%)$ \\
\hline $\begin{array}{l}\text { High dependency (HD) } \\
\text { ward }\end{array}$ & $1190(4.7 \%)$ & $872(3.7 \%)$ & $-318(-26.7 \%)$ \\
\hline $\begin{array}{l}\text { Intermediate care area } \\
\text { (ICA) }\end{array}$ & $387(1.5 \%)$ & $231(1.0 \%)$ & $-156(-40.3 \%)$ \\
\hline Intensive care unit (ICU) & $372(1.5 \%)$ & $302(1.3 \%)$ & $-70(-18.8 \%)$ \\
\hline $\begin{array}{l}\text { Infectious Disease (ID)/ } \\
\text { Isolation ward }\end{array}$ & $857(3.4 \%)$ & $1891(8.1 \%)$ & $+1034(+120.7 \%)$ \\
\hline Unknown & $658(2.6 \%)$ & $126(0.5 \%)$ & $-532(-80.9 \%)$ \\
\hline Not admitted & $\begin{array}{c}36126 \\
(58.7 \%)\end{array}$ & $\begin{array}{c}30054 \\
(56.2 \%)\end{array}$ & $-6072(-16.8 \%)$ \\
\hline Missing & 28 & 44 & \\
\hline
\end{tabular}

${ }^{1}$ Abbreviations: Q1: First quartile which represents $25^{\text {th }}$ percentile value; Q3: Third quartile which represents 75 th percentile value; P1: Priority 1; P1F: Priority 1 Fever; P2: Priority 2; P2F: Priority 2 Fever; P3: Priority 3; P3F: Priority 3 Fever; P4: Priority 4.

\subsection{Two-phase ED attendance trend}

Within the COVID-19 period, the national tally of daily infected cases started relatively small during the pre-Circuit Breaker period (Figure 2). Thereafter, the tally rocketed to its highest during the Circuit Breaker period. Figure 3 illustrates a two-phase ED attendance trend experienced at SGH ED during the pre-Circuit Breaker period and Circuit Breaker period, respectively.

\subsubsection{First phase of ED attendance trend}

Approximately one week before DORSCON Orange initiation (2 February - 8 February 2020, Week 6), there was a noticeable drop of $6.4 \%$ in weekly ED attendance (2144 vs 2291 baseline) as compared to the same week in 2019 (Figure 3). The initial downward trend in ED attendance was largely driven by the decrease in 'Non-Fever' visits. The subsequent sharp returning of ED attendance corresponded with the 
rising numbers of 'Fever' visits, even though the national tally of daily infected cases was relatively low below a hundred (Figure 2). Weekly ED attendance peaked during the last week of March, almost reaching pre-COVID-19 numbers in the same week.

\subsubsection{Second phase of ED attendance trend}

SGH ED experienced its second fall in attendance where both number of 'Fever' and 'Non-Fever' visits were declining (Figure 3). The steepest drop occurred during 3 May - 9 May 2020 (Week 19), where a $27.4 \%$ dip in ED visits was observed relative to the same week in the pre-COVID-19 period. Unlike the surge in ED attendance and number of 'Fever' visits that we observed during pre-Circuit Breaker period (First phase), ED attendance declined even as daily infected cases hit record-breaking numbers during the Circuit Breaker (Second phase) (Figure 2). Nevertheless, as the nation was halfway through Circuit Breaker, we observed a slow and steady climb in SGH ED attendance that was visually distinct from the surge in the first phase (Figure 3 ). This gradual recovery coincided with the rise in total 'Non-Fever' visits and a relatively constant number of 'Fever' visits. Following the end of Circuit Breaker and the gradual easing of restrictions for safe resumption of activities, ED attendances continued to show signs of gradual recovery to baseline numbers (Figure 3).

\subsection{Sub-group analysis of ED attendance by 'Non-Fever' and 'Fever' triage categories}

There was a decline in ED attendances across all 'Non-Fever' triage groups (P1-P4), including the sickest patient group (P1). There were $4.7 \%$ and $7.8 \%$ reductions in the proportion of $P 1$ visits $(10.0 \%$ vs $14.7 \%$ baseline) and P3 visits (19.6\% vs $27.4 \%$ baseline), respectively (Table 1, Figure S1, Supplementary Materials). In contrast, there was an increase in ED attendees across all 'Fever' triage groups. Of note, there was 8.5 times more (7636 vs 900 baseline) P3F ED visits during the COVID-19 period as compared to the Pre-COVID-19 period.

\subsection{Clinical reason for ED attendance}

Among 115,096 visit records, we excluded 2545 records (2.2\%) with no documentation of diagnosis code in our analysis of diagnoses. The remaining 112,551 visit records had a total of 143,995 documented SNOMED CT diagnosis codes. Out of these, approximately 3000 documented diagnosis codes $(2 \%)$ were not mapped to ICD-10 categories and these were excluded from our analysis.

The decline in ED attendance was accompanied by decreases in nearly every diagnosis category except for diseases of the respiratory system. The greatest reduction in proportion was seen in the diagnostic category that covers injury, poisoning and certain other consequences of external causes (Table 2). Notably, the decline in P1 visits was accompanied by a drop in presentations of severe diseases such as stroke, acute myocardial infarction, heart failure, appendicitis and paralytic ileus and intestinal obstruction without hernia. 
Table 2. SGH ED patient characteristics during the pre-COVID-19 period in 2019 and COVID-19 period in 2020.

\begin{tabular}{lccc}
\hline Time periods studied & $\begin{array}{c}\text { Pre-COVID-19 } \\
\text { period }\end{array}$ & $\begin{array}{c}\text { COVID-19 } \\
\text { period }\end{array}$ & $\begin{array}{c}\text { \% change in frequency as } \\
\text { compared to Pre-COVID- } \\
\text { 19 period }\end{array}$ \\
\cline { 2 - 3 } & $\begin{array}{c}\text { 2 Jan - 30 Jun } \\
\text { 2019 }\end{array}$ & $\begin{array}{c}\text { 1 Jan - 28 Jun } \\
\text { 2020 }\end{array}$ & \\
\hline Total No. of ED visits & 61576 & 53520 \\
No. of ED visits with $\geq 1$ recorded diagnosis & 60166 & 52385
\end{tabular}

Total No. of documented diagnoses $\quad 73545(100 \%) \quad 67444(100 \%)$

ICD-10-CM Diagnosis categories $\quad \mathrm{N}(\%$ total $\quad \mathrm{N}(\%$ total

documented documented

diagnoses) diagnoses)

\begin{tabular}{|c|c|c|c|}
\hline $\begin{array}{l}\text { Symptoms, signs and abnormal clinical and } \\
\text { laboratory findings, not elsewhere classified }\end{array}$ & $19196(25.5 \%)$ & $16883(24.5 \%)$ & $-2313(-12.0 \%)$ \\
\hline $\begin{array}{l}\text { Injury, poisoning and certain other } \\
\text { consequences of external causes }\end{array}$ & $9358(12.5 \%)$ & $6779(9.9 \%)$ & $-2579(-27.6 \%)$ \\
\hline $\begin{array}{l}\text { Diseases of the musculoskeletal system and } \\
\text { connective tissue }\end{array}$ & $5932(7.9 \%)$ & $3995(5.8 \%)$ & $-1937(-32.7 \%)$ \\
\hline Diseases of the circulatory system & $5810(7.7 \%)$ & $4723(6.9 \%)$ & $-1087(-18.7 \%)$ \\
\hline Diseases of the respiratory system & $5594(7.4 \%)$ & $11842(17.2 \%)$ & $+6248(+111.7 \%)$ \\
\hline Diseases of the digestive system & $4971(6.6 \%)$ & $4367(6.4 \%)$ & $-604(-12.2 \%)$ \\
\hline Diseases of the genitourinary system & $3821(5.1 \%)$ & $3141(4.6 \%)$ & $-680(-17.8 \%)$ \\
\hline Certain infectious and parasitic diseases & $3799(5.1 \%)$ & $3095(4.5 \%)$ & $-704(-18.5 \%)$ \\
\hline $\begin{array}{l}\text { Endocrine, nutritional and metabolic } \\
\text { diseases }\end{array}$ & $2976(4.0 \%)$ & $2735(4.0 \%)$ & $-241(-8.1 \%)$ \\
\hline $\begin{array}{l}\text { Diseases of the skin and subcutaneous } \\
\text { tissue }\end{array}$ & $2937(3.9 \%)$ & $2360(3.4 \%)$ & $-577(-19.6 \%)$ \\
\hline Diseases of the eye and adnexa & $2493(3.3 \%)$ & $1805(2.6 \%)$ & $-688(-27.6 \%)$ \\
\hline Diseases of the nervous system & $1265(1.7 \%)$ & $1074(1.6 \%)$ & $-191(-15.1 \%)$ \\
\hline Neoplasms & $1227(1.6 \%)$ & $1069(1.6 \%)$ & $-158(-12.9 \%)$ \\
\hline $\begin{array}{l}\text { Mental, Behavioral and Neurodevelopmental } \\
\text { disorders }\end{array}$ & $1012(1.3 \%)$ & $899(1.3 \%)$ & $-113(-11.2 \%)$ \\
\hline $\begin{array}{l}\text { Diseases of the blood and blood-forming } \\
\text { organs and certain disorders involving the } \\
\text { immune mechanism }\end{array}$ & $943(1.3 \%)$ & $860(1.2 \%)$ & $-83(-8.8 \%)$ \\
\hline External causes of morbidity & $699(0.9 \%)$ & $636(0.9 \%)$ & $-63(-9.0 \%)$ \\
\hline Diseases of the ear and mastoid process & $640(0.9 \%)$ & $537(0.8 \%)$ & $-103(-16.1 \%)$ \\
\hline $\begin{array}{l}\text { Factors influencing health status and } \\
\text { contact with health services }\end{array}$ & $557(0.7 \%)$ & $405(0.6 \%)$ & $-152(-27.3 \%)$ \\
\hline Pregnancy, childbirth and the puerperium & $220(0.3 \%)$ & $174(0.3 \%)$ & $-46(-20.9 \%)$ \\
\hline $\begin{array}{l}\text { Congenital malformations, deformations and } \\
\text { chromosomal abnormalities }\end{array}$ & $62(0.1 \%)$ & $36(0.1 \%)$ & $-26(-41.9 \%)$ \\
\hline \multirow{2}{*}{ Certain conditions originating in the } & $33(0.0 \%)$ & $29(0.0 \%)$ & $-4(-12.1 \%)$ \\
\hline & Page $9 / 18$ & & \\
\hline
\end{tabular}


perinatal period

Total No. of P1 visits

9049

5336

No. of $\mathrm{P} 1$ visits with $\geq 1$ recorded diagnosis

9012

5313

Total No. of recorded diagnoses

$11510(100 \%) \quad 7519(100 \%)$

ICD-10-CM Diagnosis categories

N (\% total N (\% total

documented documented

diagnoses) diagnoses)

\section{Severe diseases}

\begin{tabular}{|c|c|c|c|}
\hline Stroke & $704(6.1 \%)$ & $516(6.9 \%)$ & $-188(-26.7 \%)$ \\
\hline Acute myocardial infarction & $508(4.4 \%)$ & $440(5.9 \%)$ & $-68(-13.4 \%)$ \\
\hline $\begin{array}{l}\text { ST elevation (STEMI) myocardial } \\
\text { infarction }\end{array}$ & $226(2.0 \%)$ & $187(2.5 \%)$ & $-39(-17.3 \%)$ \\
\hline Non-STEMI (NSTEMI) & $282(2.5 \%)$ & $253(3.4 \%)$ & $-29(-10.3 \%)$ \\
\hline Other acute ischemic heart diseases & $109(0.9 \%)$ & $95(1.3 \%)$ & $-14(-12.8 \%)$ \\
\hline Heart failure & $337(2.9 \%)$ & $231(3.1 \%)$ & $-106(-31.5 \%)$ \\
\hline Cardiac arrest & $92(0.8 \%)$ & $102(1.4 \%)$ & $+10+(10.9 \%)$ \\
\hline $\begin{array}{l}\text { Paralytic ileus and intestinal obstruction } \\
\text { without hernia }\end{array}$ & $337(2.9 \%)$ & $277(3.7 \%)$ & $-60(-17.8 \%)$ \\
\hline Appendicitis & $173(1.5 \%)$ & $157(2.1 \%)$ & $-16(-9.2 \%)$ \\
\hline
\end{tabular}

${ }^{1}$ Abbreviations: ICD-10-CM: International Classification of Diseases, Tenth Revision, Clinical Modification

\section{Discussion}

Since the beginning of the COVID-19 outbreak, the overall number of SGH ED visits and admissions have dipped as compared to corresponding pre-COVID-19 period. With such a large decrease in ED visits at SGH, one may expect the sickest patients (P1) to continue attending ED for unquestionably needed emergency care. However, SGH ED saw fewer life-threatening presentations and a decrease in both the number and proportion of P1 visits throughout the COVID-19 period. Patients may have avoided SGH ED due to fear of burdening the healthcare system [20] or contracting the dreadful virus in a public hospital that is screening and treating for COVID-19 [21]. Our data, however, cannot prove whether there has been a true decrease in the incidence of diseases, or whether patients are avoiding ED or seeking treatment elsewhere. Whether there was any delay and failure in seeking urgently needed treatments remains a major public health concern as this can translate to poorer health outcomes and potentially increased the need for hospital care [22]. Amid a new wave of COVID-19 infections in the community, addressing factors contributing to the decline in ED visits may help to identify key targets of interventions for better health outcomes. 
During the first phase where daily counts of newly infected community cases were relatively low, the shift in ED patient case-mix from 'Non-fever' cases to 'Fever' cases may be contributed by suspected COVID-19 cases seeking testing and treatment at the ED, as well as patients seeking care for flu-like symptoms for fear that they have contracted the COVID-19 virus [23]. Amidst the rise in 'Fever' visits during the first phase, the overall number of 'Non-Fever' visits fell and this decline persisted into the Circuit Breaker period (Second phase). On the contrary, the surge in number of infected cases during Circuit Breaker (Second phase) was largely restricted to the densely occupied migrant worker dormitories, rather than the community [24]. The prompt gazetting of these dormitories as isolation areas, general compliance to social distancing measures, rapid contact tracing and systematic screening for COVID-19 have likely stemmed any widespread infection to the community. Moreover, the scaling up of community medical facilities and services during the Circuit Breaker (Second phase) allowed quicker testing and housing of clinically well COVID-19 patient [24]. These measures likely gained traction throughout Circuit Breaker and prevented an overwhelming number of 'Fever' visits to SGH ED, which partially explains the persistent nadir of ED attendance observed during the first half of Circuit Breaker.

In the second half of the Circuit Breaker, the recovery in 'Non-Fever' visits may be due to the delay in seeking treatment, resulting in more severe presentations that required emergent care and admission from ED. It may also be attributed to better public perception of the local COVID-19 situation and the declining number of new cases in the community back then. These may have quelled the public's fear of contracting the virus in the community and hospital settings.

The COVID-19 pandemic is still showing no signs of abating globally and the resurgence of outbreaks, as seen in many other countries, is inevitable as Singapore reopens its borders. A deeper understanding on the pandemic's indirect impact on patient outcomes and the overall demand for emergent care across the nation is needed. Further studies on patients presenting to the ED during this period are needed to fully understand the health implications of the COVID-19 outbreak. It is also essential to explore public perceptions on seeking treatment at ED during the COVID-19 period. Lastly, understanding the reasons behind the decline in low-acuity presentations may be useful for ED crowd management planning in a post-COVID-19 era.

As this was a single-centre study based on SGH's patient profile, and the analysis was performed using data collected from SGH's eHINTS-ED database, our findings may not be generalisable to other EDs in Singapore and we do not know whether more or less patients are seeking treatment at other hospitals. Although this study was not able to prove causation due to the nature of a descriptive analysis, our findings provide first insights on how ED utilisation at SGH has changed across different subperiods of 
the COVID-19 pandemic, laying out important questions and implications that future studies should address.

\section{Conclusion}

The COVID-19 pandemic caused a large decline in ED attendances at SGH, even amongst those with highest priority for emergency care. This raises the concern whether patients were delaying critically needed treatment at ED, and whether this has resulted in poorer health outcomes. This descriptive analysis revealed distinct ED visit trends across different time periods. A deeper understanding of how patients are utilising healthcare services across different healthcare institutions will guide policymakers on hospital resource planning and allocation in anticipation of worsening COVID-19 situations and in future pandemics.

\section{Declarations}

Supplementary Materials: The following are available online at www.mdpi.com/xxx/s1, Figure S1: Weekly ED attendance trend for each 'Non-Fever' triage group during the pre-COVID-19 and COVID-19 periods.

Author Contributions: Conceptualization, F.J.S. and M.E.H.O.; methodology, L.M.Q., F.J.S., S.E.S. and M.E.H.O.; formal analysis, L.M.Q.; data curation, L.M.Q., F.J.S., S.E.S., A.F.W.H., J.N.M.H.L., B.K.K.T., N.S.S. and YS.; writing-original draft preparation, L.M.Q.; writing-review and editing, F.J.S., S.E.S., A.F.W.H., J.N.M.H.L., B.K.K.T., N.S.S., Y.S. and M.E.H.O.; visualization, L.M.Q.; supervision, F.J.S., S.E.S. and M.E.H.O. All authors have read and agreed to the published version of the manuscript.

Funding: This research received no external funding.

Institutional Review Board Statement: This was a service evaluation study which did not require further ethical deliberation by SingHealth Centralised Institutional Review Board (CIRB Ref: 2020/2470).

Informed Consent Statement: Patient consent was waived as all data were de-identified by the SingHealth Health Services Research Centre (HSRC) in accordance with the Human Biomedical Research Act (HBRA) before data processing and analysis.

Data Availability Statement: The data presented in this study are available on request from the corresponding author.

Acknowledgments: I am grateful to Mr Narayanan Ragavendran, who works with the Health Services Research Centre at Singhealth, for kindly providing his expertise and service in data deidentification. I am grateful to Sherman Lian for helping with the extraction of anonymised patient data. I would also like to thank Dr Gayathri Devi Nadarajan for providing valuable insights on SGH ED's workflow. I would also like to thank A/Prof Liu Nan for providing R coding guidance and support. Lastly, I would like to express my 
gratitude to my fellow MD candidate Zhong Xun for providing guidance on the conversion of SNOMED CT diagnosis codes to ICD-10.

Conflicts of Interest: The authors declare no conflict of interest.

\section{References}

1. Hartnett, K. P.; Kite-Powell, A.; DeVies, J.; Coletta, M. A.; Boehmer, T. K.; Adjemian, J.; Gundlapalli, A. V.; National Syndromic Surveillance Program Community of Practice. Impact of the COVID-19 Pandemic on Emergency Department Visits - United States, January 1, 2019-May 30, 2020. MMWR Morb. Mortal. Wkly. Rep. 2020, 69 (23), 699-704. https://doi.org/10.15585/mmwr.mm6923e1.

2. Cella, A.; Marchetti, F.; lughetti, L.; Di Biase, A. R.; Graziani, G.; De Fanti, A.; Valletta, E.; Vaienti, F.; Vergine, G.; Viola, L.; Biasucci, G. Italian COVID-19 Epidemic: Effects on Paediatric Emergency Attendance-a Survey in the Emilia Romagna Region. BMJ Paediatr. Open 2020, 4 (1), e000742. https://doi.org/10.1136/bmjpo-2020-000742.

3. Leow, S. H.; Dean, W.; MacDonald-Nethercott, M.; MacDonald-Nethercott, E.; Boyle, A. A. The Attend Study: A Retrospective Observational Study of Emergency Department Attendances During the Early Stages of the COVID-19 Pandemic. Cureus 2020. https://doi.org/10.7759/cureus. 9328.

4. Walline, J. H.; Song, P. P.; Lim, A. M.; Hung, K. K.; Graham, C. A. Hong Kong Emergency Department Attendance Plummets during COVID -19. Emerg. Med. Australas. 2020, 32 (6), 1093-1094. https://doi.org/10.1111/1742-6723.13614.

5. De Filippo, O.; D’Ascenzo, F.; Angelini, F.; Bocchino, P. P.; Conrotto, F.; Saglietto, A.; Secco, G. G.; Campo, G.; Gallone, G.; Verardi, R.; Gaido, L.; lannaccone, M.; Galvani, M.; Ugo, F.; Barbero, U.; Infantino, V.; Olivotti, L.; Mennuni, M.; Gili, S.; Infusino, F.; Vercellino, M.; Zucchetti, O.; Casella, G.; Giammaria, M.; Boccuzzi, G.; Tolomeo, P.; Doronzo, B.; Senatore, G.; Grosso Marra, W.; Rognoni, A.; Trabattoni, D.; Franchin, L.; Borin, A.; Bruno, F.; Galluzzo, A.; Gambino, A.; Nicolino, A.; Truffa Giachet, A.; Sardella, G.; Fedele, F.; Monticone, S.; Montefusco, A.; Omedè, P.; Pennone, M.; Patti, G.; Mancone, M.; De Ferrari, G. M. Reduced Rate of Hospital Admissions for ACS during Covid-19 Outbreak in Northern Italy. N. Engl. J. Med. 2020, 383 (1), 88-89. https://doi.org/10.1056/NEJMc2009166.

6. Lange, S. J.; Ritchey, M. D.; Goodman, A. B.; Dias, T.; Twentyman, E.; Fuld, J.; Schieve, L. A.; Imperatore, G.; Benoit, S. R.; Kite-Powell, A.; Stein, Z.; Peacock, G.; Dowling, N. F.; Briss, P. A.; Hacker, K.; Gundlapalli, A. V.; Yang, Q. Potential Indirect Effects of the COVID-19 Pandemic on Use of Emergency Departments for Acute Life-Threatening Conditions - United States, January-May 2020. 2020, 69 (25), 6 .

7. Nagamine, M.; Chow, D. S.; Chang, P. D.; Boden-Albala, B.; Yu, W.; Soun, J. E. Impact of COVID-19 on Acute Stroke Presentation at a Comprehensive Stroke Center. Front. Neurol. 2020, 11, 850. https://doi.org/10.3389/fneur.2020.00850.

8. Khalik, S. Surge in Coronavirus Infections Strains Healthcare System. The Straits Times. Singapore April 18, 2020. 
9. What do the different DORSCON levels mean http://www.gov.sg/article/what-do-the-differentdorscon-levels-mean (accessed 2020 -08-15).

10. Shorey, S.; Ang, E.; Yamina, A.; Tam, C. Perceptions of Public on the COVID-19 Outbreak in Singapore: A Qualitative Content Analysis. J. Public Health 2020, 42 (4), 665-671. https://doi.org/10.1093/pubmed/fdaa105.

11. Comprehensive Medical Strategy for COVID-19 https://www.moh.gov.sg/newshighlights/details/comprehensive-medical-strategy-for-covid-19 (accessed 2020 -08-15).

12. Tay, T. F. Coronavirus: Community Cases Remain Low but Singapore Should Prepare for Second Wave, Says Gan Kim Yong. The Straits Times. Singapore July 17, 2020.

13. Singapore starts booster shots as COVID cases hit 1-year high https://asia.nikkei.com/Spotlight/Coronavirus/COVID-vaccines/Singapore-starts-booster-shots-asCOVID-cases-hit-1-year-high (accessed 2021 -09-14).

14. Govt won't rule out return to circuit breaker or heightened alert if Covid-19 cases in ICUs rise sharply: Lawrence Wong https://www.todayonline.com/singapore/govt-wont-rule-out-return-circuit-breaker-orheightened-alert-if-covid-19-cases-icus-rise (accessed 2021 -09-06).

15. Quah, L. J. J.; Tan, B. K. K.; Fua, T.-P.; Wee, C. P. J.; Lim, C. S.; Nadarajan, G.; Zakaria, N. D.; Chan, S.-E. J.; Wan, P. W.; Teo, L. T.; Chua, Y. Y.; Wong, E.; Venkataraman, A. Reorganising the Emergency Department to Manage the COVID-19 Outbreak. Int. J. Emerg. Med. 2020, 13 (1), 32. https://doi.org/10.1186/s12245-020-00294-w.

16. Fong, R. Y.; Glen, W. S. S.; Mohamed Jamil, A. K.; Tam, W. W. S.; Kowitlawakul, Y. Comparison of the Emergency Severity Index versus the Patient Acuity Category Scale in an Emergency Setting. Int. Emerg. Nurs. 2018, 41, 13-18. https://doi.org/10.1016/j.ienj.2018.05.001.

17. SNOMED CT to ICD-10-CM Map https://www.nlm.nih.gov/research/umls/mapping_projects/snomedct_to_icd10 cm.html (accessed 2020 -09-27).

18. R: The R Project for Statistical Computing https://www.r-project.org/ (accessed 2020 -04 -30).

19. Past Updates on COVID-19 Local Situation https://www.moh.gov.sg/covid-19/past-updates (accessed $2020-08-15$ ).

20. Singaporeans are confident in the Government amidst fears of the COVID-19 outbreak https://www.ipsos.com/en-sg/singaporeans-are-confident-government-amidst-fears-covid-19outbreak (accessed $2020-08-16$ ).

21. Wong, L. E.; Hawkins, J. E.; Langness, S.; Iris, P.; Sammann, A. Where Are All the Patients? Addressing Covid-19 Fear to Encourage Sick Patients to Seek Emergency Care. 2020, 12.

22. Czeisler, M. É.; Marynak, K.; Clarke, K. E. N.; Salah, Z.; Shakya, I.; Thierry, J. M.; Ali, N.; McMillan, H.; Wiley, J. F.; Weaver, M. D.; Czeisler, C. A.; Rajaratnam, S. M. W.; Howard, M. E. Delay or Avoidance of Medical Care Because of COVID-19-Related Concerns - United States, June 2020. 2020, 69 (36), 8.

23. Inside Singapore's COVID-19 screening centre, on the front line against the disease https://www.channelnewsasia.com/cnainsider/inside-singapore-covid-19-screening-centre-defence- 
disease-ncid-765381 (accessed 2020 -04 -19).

24. Stretched but coping: How Singapore's healthcare system has cranked up efforts to deal with COVID19 https://www.channelnewsasia.com/singapore/covid-19-singapore-health-capacity-hospitalstreatment-935336 (accessed $2020-05-04)$.

\section{Figures}

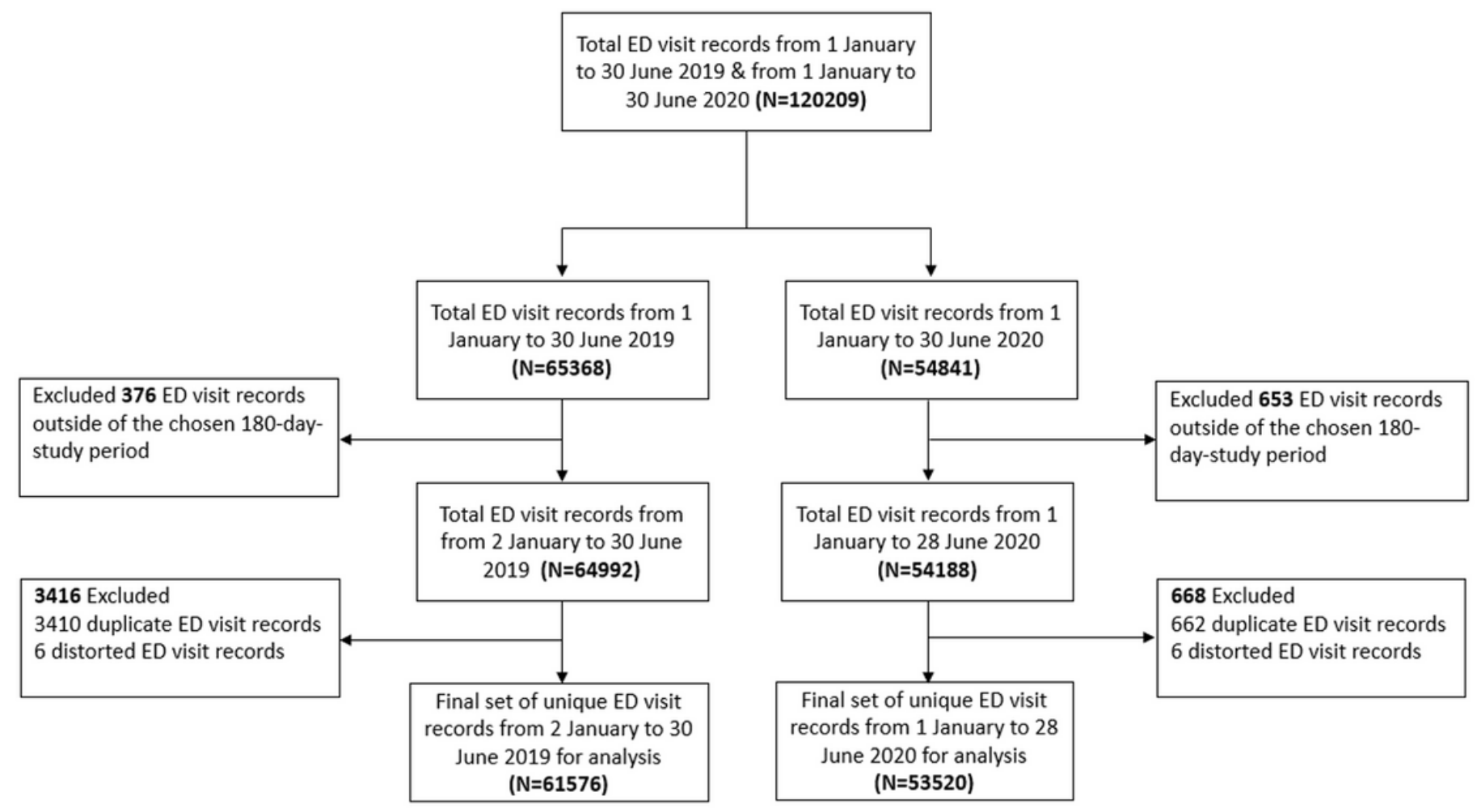

${ }^{1}$ Abbreviations: ED: Emergency department; N: number of records.

\section{Figure 1}

Flowchart depicting study selection process of ED visit records for analysis. 


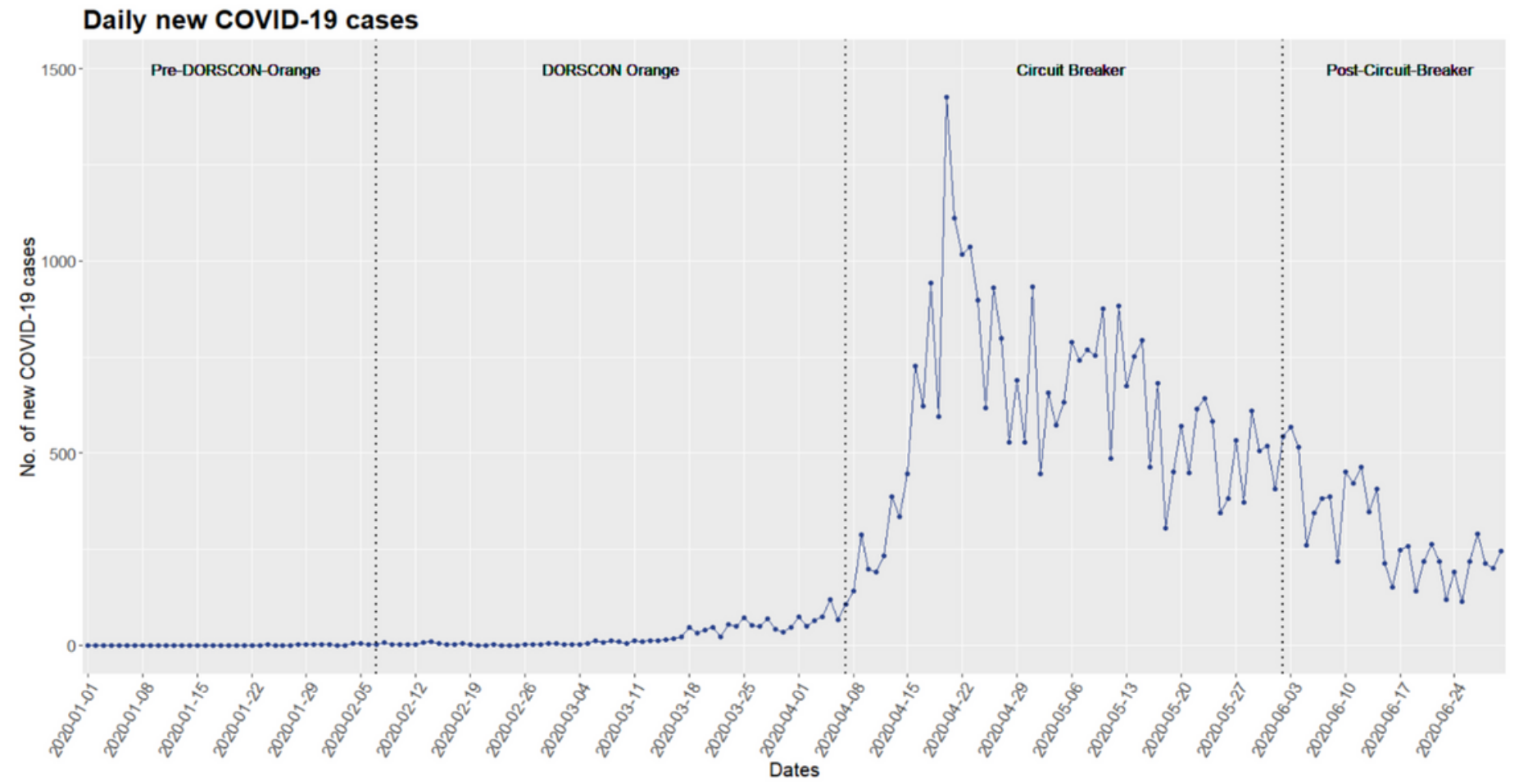

${ }^{1}$ Source: Ministry of Health (MOH) Singapore, Past updates on COVID-19 (Coronavirus disease 2019) local situation, 2020 [19].

\section{Figure 2}

An illustration of the trend of daily newly infected cases in Singapore. 


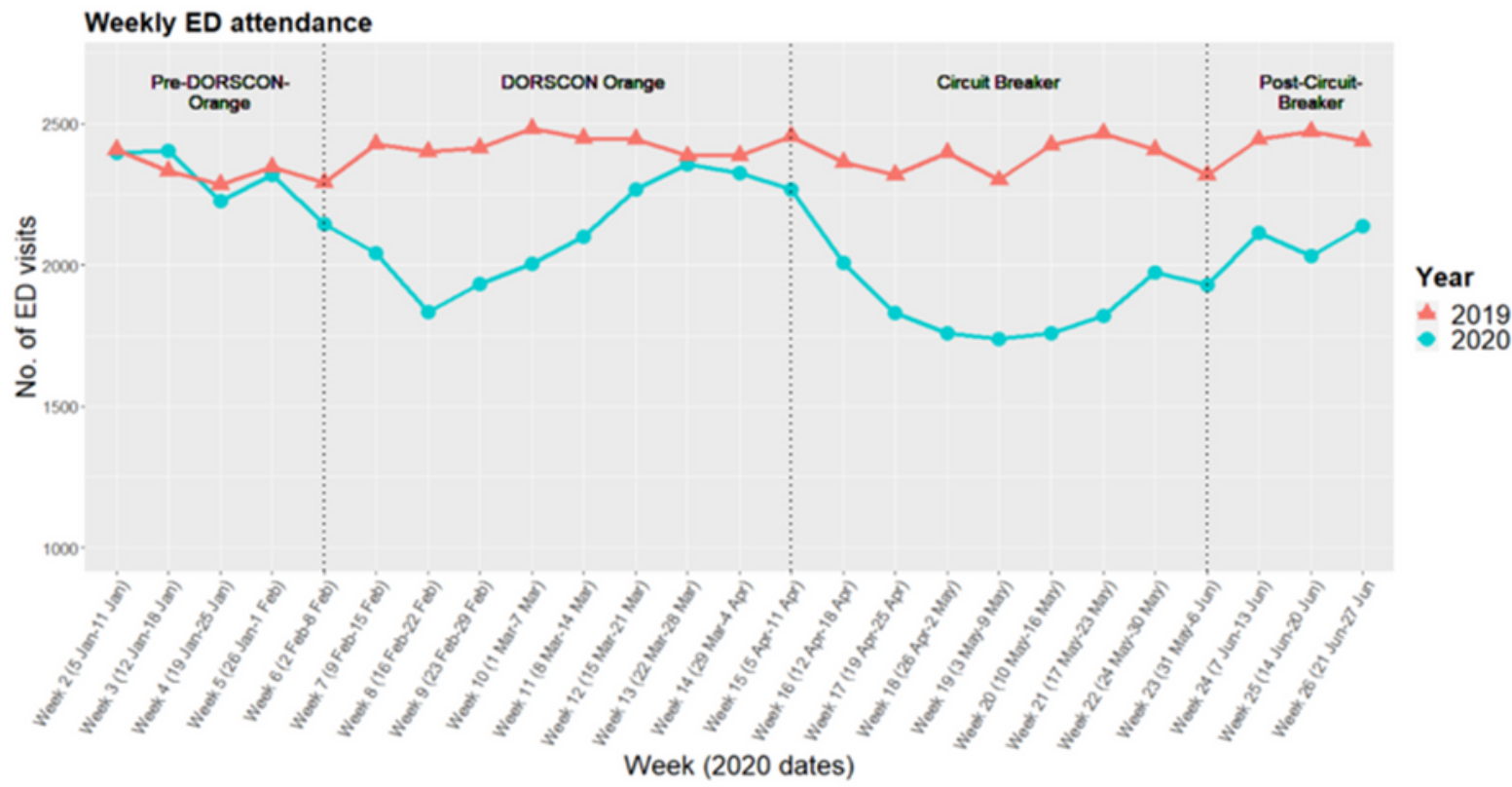

Weekly ED attendance by Triage Class - Fever vs Non-Fever visits

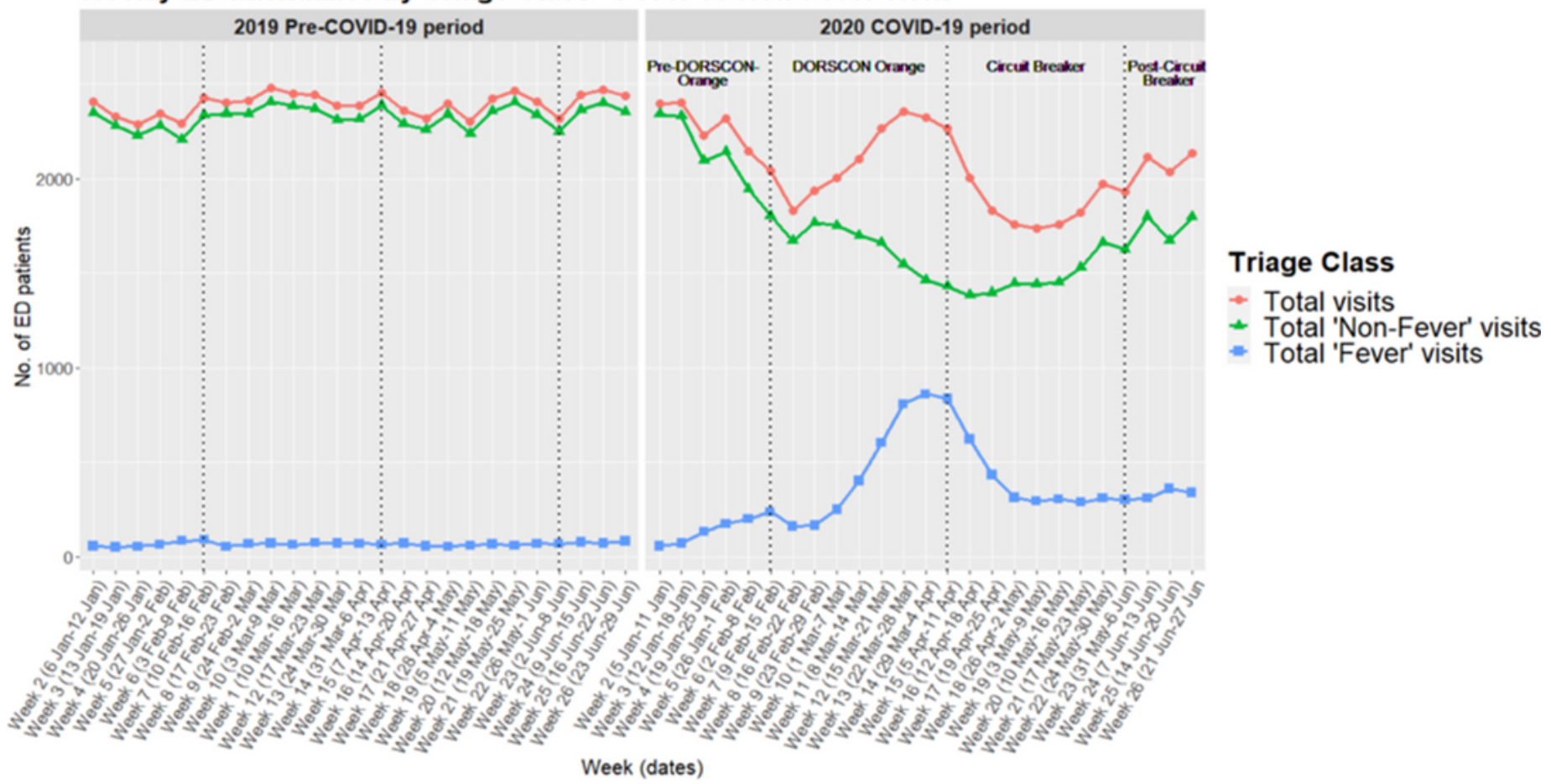

${ }^{1}$ Epi-weeks were used for plotting and only completed epi-weeks 2 to 26 of each studied period were included in this figure.

\section{Figure 3}

Weekly SGH ED attendance by year and by febrile triage status during the studied COVID-19 period and its corresponding historical pre-COVID-19 period.

\section{Supplementary Files}


This is a list of supplementary files associated with this preprint. Click to download.

- FigureS1.png 